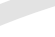
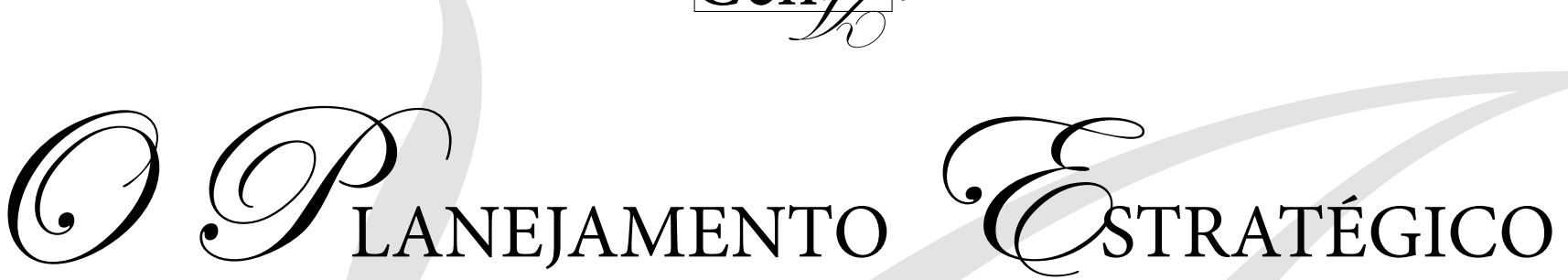

\section{E O CONCEITO DE PERFORMANCE PROCESS NA GESTÃO DAS ARTES}

\author{
"The Strategic Planning And The Performance \\ Process Concept in Artistics Management"
}

\author{
Valquiria Guimarães Duarte* \\ Professora de Artes Integradas, Cenografia e Arquitetura \\ da Universidade Federal de Goiás \\ Consultora do Ministério Público do Estado de Goiás
}

\begin{abstract}
RESUMO: Uma das questões atuais na discussão sobre gestão das ações de cunho artístico está na problemática que envolve metodologias de criação e realização dos diversos tipos de propostas, sejam elas de espetáculos performativos (teatro, dança), sejam de espetáculos de natureza expositiva (exposições de arte, museais ou não - cabendo aqui todo tipo de manifestações que ocupam um espaço da galeria, teatro, museu ou cidade). Sabendo que o planejamento estratégico tem sido um campo de debates frutíferos na área da arquitetura, e tendo como exemplo experiências exploradas em países diversos (no Brasil, um empreendimento fomentado há pouco tempo), voltamo-nos a uma interlocução entre os campos da Arquitetura/construção civil e da Arte para embasar nossa proposta: trazer a experiência de Gestão Estratégica da área da Arquitetura para o campo da Arte. Gestar e gerir ações artísticas, dar forma e realizá-las preservando ao máximo os desejos do autor são os elementos "chave" desse artigo. Nesse sentido, buscamos na Gestão Estratégica uma metodologia possível para a otimização de ações artísticas - e, de passagem, aproveitamos a exploração do conceito no conhecimento do processo, para uma hermenêutica/crítica. Para tanto, apoiamo-nos no conceito de Performance Process (DUARTE, 2013) como base para nosso empreendimento.
\end{abstract}

Palavras-chave: Gestão em Arte; Gestão Estratégica; Performance Process; Transdisciplinaridade.

ABSTRACT: One of the current issues in the discussion on actions of artistic's managements is the problem involving methodologies creation and realization of various types of proposals, whether of performative shows (theater, dance, cinema), whether expositions shows (art exhibitions, museological or not - fitting here all types of events that occupy a gallery space, theater, museum or city). Knowing that strategic planning has been a fruitful debate in the architecture field, and with experiences already explored in several countries (in Brazil, the debate is fomented recently), we turn to a dialogue between the fields of Architecture and Art to base our proposal: bring the Strategic Management experience in architecture and civil construction to the field of art. Gestate and manage artistic actions, perform them preserving the most of the author's wishes are the elements "key" of this article. In this sense, we seek the strategic management how a possible methodology for optimizing of performative actions and, in passing, we took the deepening knowledge of the artistic process to a hermeneutic / criticism. Therefore, we use the concept of Performance Process (DUARTE, 2013), as the basis for our business.

KEYWORDS: Artistic Management, Strategic Management; Performance Process, Transdisciplinarity.

Valquiria Guimarães Duarte - O Planejamento Estratégico e o Conceito de Performance Process na Gestão das Artes Revista Arte da Cena, Goiânia, v. 2, n. 2, p. 82-97, Jan.-Jun./2016

Disponível em: http://www.revistas.ufg.br/index.php/artce 


\section{INTRODUÇÃO}

Aprodução artística contemporânea se apresenta em diferentes linguagens, cada vez mais contaminadas por diferentes mídias. Muitas vezes a produção ou processo carecem de um conhecimento interdisciplinar que dê forma às aspirações do criador, ou mesmo que lhe dê condições apropriadas de acesso a exigências de programas de fomento à cultura. Cada vez mais complexas, elas dependem de noções de diferentes áreas de atuação para serem otimizadas conforme o conceito adotado, desde o princípio, pelo autor. Muito da produção artística acaba por ser efetivada de forma amadora, prejudicando as intenções do artista, do produtor ou do curador. Esse assunto interessa aos estudos interartísticos (CLUVER; NORONHA), uma vez que a criação em arte, acompanhada de um planejamento e realização de qualidade, tem a capacidade não só de qualificar obras subsequentes, como também refletir todos os detalhes e desejos do autor ${ }^{1}$.

Uma das questões atuais na discussão sobre gestão das ações de cunho artístico está na problemática que envolve metodologias de criação e concretização/realização dos diversos tipos de propostas, sejam elas de espetáculos performativos (teatro, dança, vídeo arte, cinema), sejam de espetáculos de natureza expositiva (exposições de arte, museais ou não - cabendo apontar aqui todo tipo de manifestações que ocupam o espaço do corpo, do objeto, da galeria, do teatro, do museu e da cidade). Sabendo que o Planejamento Estratégico em arquitetura tem sido um campo de debates frutíferos na área do planejamento e construção civil, e tendo como exemplo experiências já exploradas em diversos países (no Brasil é um empreendimento há pouco tempo iniciado), voltamo-nos a uma interlocução entre os campos da Arquitetura/ Construção Civil e da Arte para nos embasar em nossa proposta de gestão estratégica em arte: trazemos a experiência da Gestão Estratégica em Arquitetura para o campo das Artes. Propor uma metodologia de planejamento e gestão de ações artísticas, preservando ao máximo seu conceito e proporcionando a estrutura necessária para a complexidade exigida pelas produções atuais: esse é o objetivo desse artigo. Para tanto, buscamos na Gestão Estratégica um método possível para a otimização da obra de arte.

\section{A GESTÃO ESTRATÉGICA NA ARQUITETURA E CONSTRUÇÃO CIVIL}

Antes de nos aproximarmos ao tema da gestão estratégica em artes buscamos o conceito de Performance Process ${ }^{2}$, que problematiza o campo do arquitetura e construção civil, para então procurar semelhanças com as ações artísticas atuais e operar uma operação transdisciplinar. $\mathrm{O}$

Valquiria Guimarães Duarte - O Planejamento Estratégico e o Conceito de Performance Process na Gestão das Artes Revista Arte da Cena, Goiânia, v. 2, n. 2, p. 82-97, Jan.-Jun./2016 
conceito visa entender o trajeto de efetivação de uma obra, da ideia inicialà sua realização - ou seja, é a memória construtiva do processo -, que passa por etapas oriundas da prática construtiva, atualmente incrementada pelo Planejamento Estratégico / Gestão Estratégica, metodologia desenvolvida como condição necessária ao atual quadro do planejamento e construção civil, cada vez mais complexo e repleto de novidades tecnológicas ${ }^{3}$.

Quando se vê uma obra de arquitetura finalizada, principalmente as de grande proporção, dificilmente se tem ideia da complexidade do trajeto percorrido. O que denominamos "fase da construção" de um edifício evidencia um percurso que inicia muito antes, e muitasvezes não é linear: é no processode realização da obra que se confronta a fantasia inicial do autor frente às demandas da realidade. No ato de efetivação aparecem desafios de toda ordem: nesse momento questionamos nossa tecnologia, a qualificação dos profissionais, a qualidade do material, a logística, os custos. É também nesteprocesso que o arquiteto retifica o projeto, modifica detalhes, faz as últimas escolhas.

A obra arquitetônica, ao contrário de ser pensada em sua incompletude e a incompletude pensada como uma virtude - se pensa como obra acabada. Em outras palavras, o processo arquitetônico é tomado também pelo acaso, por mais que uma obra seja planejada. Muito da arquitetura contemporânea se torna acidente; muito de sua produção no Brasil (e não só no Brasil), por mais que seja planejada como um todo é também tomada pelo acaso, e ao final do processo, se efetiva em sua incompletude, deixando marcas pelo caminho. Muitas vezes as mudanças de trajeto implicam um desvirtuamento do projeto inicial. Nesse sentido, a obra efetivada incorpora as vicissitudes do caminho, os acasos das mudanças de rumo no decorrer da construção, o atravessamento de multiplicidades, produzindo "outra" cena no canteiro de obras, na qual o acidente ou as rachaduras configuram-se em realidades existenciais.

Assim, quanto menos a obra é planejada antes de sua realização, mais o arquiteto e a empreiteira, ao se apropriarem do sítio, caem em "outro" terreno. Ou seja, outras realidades surgem durante uma obra: a coexistência do linear e do não hierárquico no processo de concretização de um edifício é um fator a se avaliar. Ou seja, considerando que já há uma ordem secreta do caos e do imprevisto dentro da ordem linear da construção, podemos inferir a necessidade de um Planejamento Estratégico para minimizar os desvirtuamentos do projeto. Ressaltamos que alguns processos criativos em arquitetura (e em arte também) se efetivam com a obra em

Valquiria Guimarães Duarte - O Planejamento Estratégico e o Conceito de Performance Process na Gestão das Artes Revista Arte da Cena, Goiânia, v. 2, n. 2, p. 82-97, Jan.-Jun./2016 


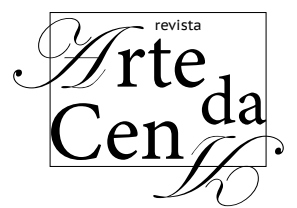

DOI: http://dx.doi.org/10.5216/ac.v2i2.42310

andamento, como os detalhamentos. Deste modo, as mudanças de rumo e adaptações fazem parte do processo construtivo e devem ser considerados em qualquer planejamento.

Para Melhado (2010, p.1) o Planejamento Estratégico compreende: o estabelecimento dos objetivos e parâmetros a serem seguidos nos projetos; a definição dos escopos de projeto, segundo especialidades e etapas; o planejamento dos recursos para desenvolvimento dos projetos; o planejamento de todas as etapas e prazos, para a definição do cronograma, por etapa, e global, do projeto e obra. A gestão de um projeto inclui

“... controlar e adequar os prazos planejados para desenvolvimento das diversas etapas e especialidades de projeto (gestão de prazos); controlar os custos de desenvolvimento dos projetos em relação ao planejado; fomentar e garantir a qualidade das soluções técnicas adotadas nos projetos; validar (ou fazer validar pelo empreendedor) as etapas de desenvolvimento e os projetos dela resultantes; fomentar a comunicação entre os participantes do projeto, coordenar as interfaces e garantir a compatibilidade entre as soluções das várias especialidades envolvidas no projeto; integrar as soluções de projeto com as fases subsequentes do empreendimento, nas interfaces com a execução e com a fase de uso,operação e manutenção da obra" (MELHADO, 2012, p.1).

Os grupos de processos do que se denomina project management ${ }^{4}$, de uma maneira geral, são 5: 1-Início; 2 - Planejamento; 3- Execução;
4- Monitoramento e Controle; 5- Encerramento. Já o conhecimento em gerenciamento de projetos é composto de aproximadamente dez áreas, que se adéquam à missão que se deve atingir:Gerenciamento da Integração; Gerenciamento de Escopo; Gerenciamento de Custos; Gerenciamento de Qualidade; Gerenciamento das Aquisições; Gerenciamento de Recursos Humanos; Gerenciamento das Comunicações; Gerenciamento de Risco; Gerenciamento de Tempo; Gerenciamento das Partes Interessadas. Embora tenha uma abrangência de ação, a project management traz um foco único delineado pelos objetivos, recursos e a programação de cada projeto - de cada “missão". Em outras palavras, o gerenciamento darestrição triplade projetos, que são o custo, tempo e o escopo.

Na gestão estratégica, o diálogo entre os profissionais de diversas áreas, coordenados por um project manager ${ }^{5}$,acontece não só após a finalização do projeto, mas durante todo o desenvolvimento do processo criativo. Isso demonstra a necessidade do trabalho colaborativo entre as áreas envolvidas no projeto, para se otimizar o empreendimento. $\mathrm{Na}$ arquitetura, por exemplo, a consultoria com diferentes profissionais durante o processo de desenvolvimento do Anteprojeto $^{6}$, não só viabiliza a proposta do arquiteto, no tocante à estrutura, instalações e

Valquiria Guimarães Duarte - O Planejamento Estratégico e o Conceito de Performance Process na Gestão das Artes Revista Arte da Cena, Goiânia, v. 2, n. 2, p. 82-97, Jan.-Jun./2016 
tecnologias, mas viabiliza a estética do edifício, ou seja, proporciona que o arquiteto atinja seu objetivo final, que é o de imprimir no espaço uma linguagem com o acabamento desejado. É importante ressaltar essa questão, uma vez que no Brasil nem sempre os arquitetos trabalham com consultores na fase dos estudos, mesmo em projetos de grandes dimensões. Por isso, na fase de aprovação e execução surgem problemas de toda ordem, e consequentemente, modificações durante a obra: são as "re" formas que já acontecem no trajeto construtivo. Na finalização, o edifício já apresenta marcas de um planejamento precário, mostrando marcas e adaptações ao uso.

Segundo o Planejamento Estratégico, a participação das diferentes áreas de conhecimento durante, e não após a finalização do projeto, é imprescindível, principalmente nos que incluem muitos aspectos tecnológicos. A project management, nesse sentido, influencia a estratégia do desenvolvimento de projetos, uma vez que o project manager, como interlocutor, faz a ponte entre as necessidades do projeto e as diferentes especialidades solicitadas à cada etapa projetiva. Este, por sua vez,deve trabalhar, preferencialmente, com diferentes consultorias, integrando os profissionais à ideia do projeto, com o objetivo de otimizá-lo e adaptá-lo ao local de sua realização (tendo em vista também sua aprovação, se for o caso). A integração entre o project manager e os profissionais consultores, sua participação em todas as fases do projeto, como interlocutor, e seu acesso à ferramentas necessárias para a qualificação da obra são responsáveis pela eficácia da fase construtiva (e ainda assim a obra é tomada pelos percalços comuns, "de obra") ${ }^{7}$. Medeiros e Melhado (2013) afirmam que

\begin{abstract}
"A função de gestor do processo de projeto, antes exercida pelo arquiteto/autor do projeto, tem sido conduzida por gerenciadoras e, em muitos casos, por construtoras, que têm desenvolvido competências para a gestão do empreendimento como um todo, como estratégia de criação de valor para seus clientes e diferencial competitivo, não se limitando apenas à gestão do processo de produção da edificação.A gestão do processo de projeto da edificação muitas vezes é conduzida apenas para controle das entregas dos projetos [...] quando deveria abranger o planejamento do processo de projeto, gestão das informações (armazenamento e transmissão), documentação final do produto (projeto) e, principalmente, garantia da integração de todos os agentes envolvidos no processo" (MEDEIROS e MELHADO, 2013, p.5).
\end{abstract}

No Brasil, o atual cenário da área da construção civil aponta para mudanças no âmbito organizacional, com vistas à melhoria da produtividade e competitividade, e algumas obras de grande proporção (seriadas ou de natureza irrepetível) são o "termômetro" dessas mudanças. ${ }^{8}$ Por isso, a coordenação de projetos (a ideia de incorporar o project manager) envolve não só funções gerenciais, fomentando a integração e a cooperação entre os profissionais envolvidos,

Valquiria Guimarães Duarte - O Planejamento Estratégico e o Conceito de Performance Process na Gestão das Artes Revista Arte da Cena, Goiânia, v. 2, n. 2, p. 82-97, Jan.-Jun./2016 
mas funções técnicas, relacionadas à solução e execução do projeto.

Nos países desenvolvidos o tempo de projeto (planejamento) chega a ser igual ao tempo dedicado à obra, evitando as deficiências e desperdícios comuns na fase da execução e obtendo um melhor desempenho final. Segundo Mendonça et al, no Brasil não ocorre esta prática, "o projeto [planejamento] é visto como "mal necessário" por exigências legais, fazendo com que parte das decisões cabíveis em projeto seja tomada durante a execução" (2010, p.2) ${ }^{9}$. A atual realidade da arquitetura e construção civil demonstra uma tendência à prática do planejar estratégico como subsídio eficiente à produção do canteiro de obras. O projeto com um alto nível de informações, formuladas, estudadas e detalhadas, possibilita um cronograma mais seguro, e consequentemente, $\mathrm{o}$ fechamento dos custos.

Os estudos de viabilidade, estrategicamente efetivados nas etapas de planejamento, permitem a redução de ocorrências de falhas e de custos:

\footnotetext{
“as etapas avançam do geral para o particular, onde a liberdade de decisão entre alternativas é gradativamente substituída pelo detalhamento das soluções adotadas com a participação das diferentes especialidades de projetos" (MENDONÇAet al, 2010, p.2).
}

$\mathrm{Na}$ arquitetura (como veremos também, nas ações artísticas) a etapa do desenvolvimento dos Projetos Executivos ${ }^{10}$, a participação abrange um grupo maior de profissionais especializados, que detalham o projeto de modo a proporcionar todas as informações necessárias a sua realização. A coordenação de projetos tem como meta a realização das soluções técnicas propostas pelos projetistas das diferentes especialidades, que estejam em consonância com os objetivos e necessidades da obra. Os projetos complexos, principalmente - aqueles que incluem inovações tecnológicas -, exigem a pesquisa de profissionais e empresas habilitadas para sua realização.

A gestão estratégica se torna um recurso que também possibilita a análise e crítica da obra quando se trata da idealização e planejamento, e no tocante as suas potencialidades e tecnologias construtivas. Segundo Mendonça et al (2010), a tradição no trato de projetos arquitetônicos no Brasil - imposta pela "cultura arquitetônica" e muitas vezes pela realidade que se impõe no mercado da construção civil (aqui queremos dizer, problemas na obra como resultado de planejamento genérico) -, confirma a importância do planejamento estratégico noempreendimento arquitetônicos. A análise do planejamento e efetivação de um edifício se torna indispensável à sua compreensão, visto que no processo se encontram várias realidades: há um enfrentamento entre a tecnologia, a logística, a disponibilidade

Valquiria Guimarães Duarte - O Planejamento Estratégico e o Conceito de Performance Process na Gestão das Artes Revista Arte da Cena, Goiânia, v. 2, n. 2, p. 82-97, Jan.-Jun./2016 
de profissionais, os custos, o cronograma. $\mathrm{Na}$ arquitetura, é nesse momento que se analisa a performance dos profissionais da construção civil, da construtora, dos fornecedores, etc., e todas as tensões que decorrem do ato de construir. E acima de tudo se analisa a performance e conceito do autor, sua capacidade de administrar e dar forma à necessidades de cunho funcional e estético.

\section{GESTÃO ESTRATÉGICA COMO PARÂMETRO}

PARA OTIMIZAÇÃO DE AÇÕES ARTÍSTICAS.

\section{UM EMPREENDIMENTO POSSÍVEL}

No trato da gestão de artística podemos dizer que atualmente há uma urgência na profissionalização da área, no que diz respeito à realização de empreendimentos de diferentes abordagens. O planejamento e o projeto, ao idealizarem e permearem todo o ciclo de vida da “ação artística" pode atuar como "registro" dos requisitos do artista, e como meio de comunicação entre todos agentes envolvidos na realização da obra. O planejamento estratégico funciona também como uma organização de meios de produção, como por exemplo, as restrições "custo, tempo e o escopo", uma vez que uma ação artística contemporânea (mesmo as propostas mais simples) apresentam requisitos técnicos, logísticos, estruturais, legais ou normativos, e de custo total, para conseguirem ser realizadas.
Será que podemos traçar um modus operandis estratégico para o campo das artes? Dada à característica multifacetada e multimídia dos empreendimentos artísticos atuais, sim, principalmente porque muitas das obras, para serem implementadas, dependem de recursos oriundosde programas de fomento à cultura. A produção artística, atualmente, é caracterizada pela hibridização de meios, por diversas linguagens conceituais, onde a tecnologia é um aliado de força. Mesmo as ações que envolvem um trabalho mais artesanal, exigem o conhecimento de tecnologias e meios específicos, muitas vezes desconhecidos pelo próprio autor. As ações artísticas que abrangem performance, teatro, dança cênica, até ocupação multimídia em galerias, museus e cidade - incluindo objetos até instalações complexas -, revela um cenário propício para se falar em "gestão estratégica", uma maneira específica no trato da obra de arte: como uma missão a ser cumprida, no sentido de sua realização dentro da previsão de cronogramas e custos.

Muitas dessas obras, para serem concretizadas, dependem de recursos oriundos de programas de fomento à cultura, que trazem em seus editais, exigências que demonstram um processo complexo desde o início. Uma vez aprovada, em edital ou não, a proposta artística demanda certa organização para que saia do

Valquiria Guimarães Duarte - O Planejamento Estratégico e o Conceito de Performance Process na Gestão das Artes Revista Arte da Cena, Goiânia, v. 2, n. 2, p. 82-97, Jan.-Jun./2016 


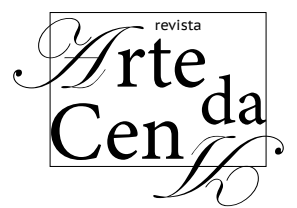

DOI: http://dx.doi.org/10.5216/ac.v2i2.42310

papel. Cabe aqui ressaltar que a estratégia de produção pode ser usada para a mais simples obra de arte. Nesse sentido, o planejamento estratégico, além de impactar na qualidade do produto final, produtividade em sua execução, pode também influenciar nos custos da manutenção, da operação e da itinerância, se for o caso.

O planejamento artístico deveria ser entendido não como um custo, mas como um investimento, cujo retorno será refletido na melhor qualidade da obra e na maior eficiência na produção - diminuindo prazos e custos finais. Seja uma obra com ou sem fins lucrativos, a "cena" artística contemporânea não mais prescinde de uma organização profissionalizada.

O planejamento estratégico em arte contribui com a organização das ações em fases (que podem acontecer simultaneamente, dependendo do caso), que se iniciam antes mesmo do conceito da obra ser finalizada. No caso de uma peça teatral ou produção de vídeo/ cinema, por exemplo, muitos projetos se iniciam com um argumento inicial, podendo ser um livro. Aí entra em ação o project manager, a quem é dada a responsabilidade de "tocar o projeto", ou seja, tratar dos desdobramentos para que a obra seja realizada conforme desejos do artista ou curador $^{11}$. Tendo como missão a realização da obra e a análise e controle final, o project manager coordenará a realização/contratação/terceirização de todos os serviços necessários à produção de determinada ação artística. Nesses termos, o artista pode se tornar um project manager, desde que se especialize em ações de gestão, e tenha conhecimento mais abrangente sobre a efetivação do empreendimento como missão (ou negócio, no jargão administrativo, business).

O project manager, na arte, é o profissional com uma visão de organização em perspectiva, que guarda conhecimento do processo e suas restrições desde o início, e faz uso das ferramentas organizacionais e gerenciais para atingir uma meta, ou seja, realizar, de maneira pró-ativa, a ação artística. Alguns dos objetivos desse gerente abrangem:

1 - Confiança e retroalimentação business: ganhar a confiança do autor/artista, desenvolvendo um escopo de atividades que atendam a demanda da obra;

2 - Decisão em potência: coordenar a equipe realizadora, de modo a permitir que os profissionais contratados possam colaborar nas decisões sobre a metodologia, equilibrando atividades com o cronograma, recursos e orçamento.

3 - Organização em perspectiva: considerar o impacto das decisões de projeto sobre a organização de custos.

Valquiria Guimarães Duarte - O Planejamento Estratégico e o Conceito de Performance Process na Gestão das Artes 
4 - Responsabilidade e responsabilidade compartilhada: criar uma relação de lealdade e visão compartilhada com o artista, bem como com os profissionais participantes do processo.

5 - Cooperação dos interessados: organizar ligações profissionais (e pessoais) com as partes interessadas, interna e externamente ao projeto.

6 - Proatividade: tomar como abordagem principal a iniciativa de localizar problemas e soluções durante a gestão do projeto.

7 - Gestão de risco: equilibrar compensações entre o escopo e riscos de projeto.

8-Gestão de tempo: motivar os participantes para o valor do tempo na tomada de decisões de execução do projeto, realizando reuniões e solicitando mudanças necessárias, dentro do cronograma previsto.

9 - Reutilizar: quando possível e pertinente, utilizar o sistema e ferramentas desenvolvidas para novos empreendimentos, de modo a acrescentar e qualificar as ações subsequentes ${ }^{12}$.

Sabendo que uma ação artística contemporânea (uma exposição, uma ocupação, uma peça de teatro, uma obra de dança, etc.) requer o trato de um negócio (business), a gestão estratégica pressupõe também uma gestão de portfólios. O que seria essa gestão na área das artes? A gestão de portfólios diz respeito à seleção de projetos a serem gerenciados - usando técnicas de gestão como meio de se chegar a resultados possíveis, dentro de um determinado contexto. Ou seja, muitas propostas de ações artísticas apresentam riscos, dificuldades técnicas ou de recurso, problemas que dificultam ou inviabilizam sua realização. São os empreendimentos vulgarmente conhecidos como "elefantes brancos" da arte, diante das possibilidades do contexto. Muitos artistas não tem noção de custos, prévios ou em perspectiva, parciais ou globais; ao final do processo, a obra é realizada precariamente, e ao artista sobram os prejuízos. Cabe à gestão de portfólios essa atividade, a de escolher projetos possíveis de serem enfrentados, criando as condições necessárias para que a sua realização, sem prejuízo à ideia inicial do autor. É possível observar que muitas obras de arte, como por exemplo, as instalações artísticas multimídias, se iniciam com uma ideia e finalizam com outra, ou terminam por serem montadas com expografia precária, suportes técnicos amadores. Quando essa parafernália não é intencional, a finalização da obra prejudica o percurso do artista, ou deixa, em aberto, a interpretação do espectador.

Alguns exemplos da precariedade que ronda a produção nas artes no Brasil são as instalações que deixam, à mostra, a "área" técnica sem que esta seja a intenção do artista. Fitas adesivas, carpetes enrugados e todo tipo de extensões são usados quando não se planeja a montagem de forma estratégica. Outro exemplo

Valquiria Guimarães Duarte - O Planejamento Estratégico e o Conceito de Performance Process na Gestão das Artes Revista Arte da Cena, Goiânia, v. 2, n. 2, p. 82-97, Jan.-Jun./2016 
são as montagens teatrais, que não planejam a cenografia em consonância com o conceito da obra. Uma produção minimalista requer um refinamento de conceito e acabamento de indumentária, sonoplastia, iluminação, definição de texturas e relevos. Para se conseguir as "cores e tons" do conceito da obra são necessários muitos conhecimentos técnicos e conceituais. E muito deste conhecimento deve ser tratado em forma de "rede". Cabe ao project manager orquestrar todas essas atividades, das ações aos profissionais encarregados na produção.

A gestão estratégica nas artes também inclui toda a visibilidade que se tem como objetivo no processo. Questões relacionadas à comunicação, distribuição e reverberação da obra na localidade (ou além), também estão previstas no gerenciamento da obra. E essa fase acontece simultaneamente a todas as outras. Quando especificamos "fase" na gestão de projetos, estamos falando de "gerências", e não de etapas. No caso da ação artística, as atividades de comunicação são muito importantes, visto que observamos muitas ações planejadas, mas esvaziadas devido à dificuldade de lidar com o âmbito do marketing - pessoal e de grupo.

Colocamos aqui um dilema: poderíamos tratar a arte como um negócio a ser administrado por outrem? Há pouco tempo esse assunto seria impensável no campo das artes. Discorrer sobre o artista enquanto administrador e negociador de sua obra (em todos os sentidos do termo), e mais, discorrer sobre $\mathrm{o}$ ato de passar a responsabilidade de realização da obra para um project manager pode parecer impensável: muitos artistas não aceitam que sua obra saia de seu campo de visão. É importante ressaltar que essa preocupação é pertinente, uma vez que tocamos no assunto "autoria", e a autoria deve ser preservada tanto quanto possível quando a obra é de autoria de um único artista. O que não significa que ele ou um project manager não possam ser os responsáveis (um ou outro) em dar forma ao empreendimento. Nesse caso, a gestão estratégica também é a responsável para que a obra se preserve "autoral", resguardando o projeto inicial e se responsabilizando por toda a burocracia e termos de condições e trabalho, definindo os lugares e papéis de cada profissional no processo, preservando o autor de sua maior preocupação: perder o controle da sua obra.

Outro ponto a ressaltar é a gestão virtual de projetos: muitas ações estratégicas se utilizam de recursos de softwares para auxiliarem no planejamento, organização de meios e gerenciamento de recursos, desenvolvendo estimativas e considerando riscos. Dependendo da sofisticação do programa, sua funcionalidade pode incluir estimativas, programação e controle de

Valquiria Guimarães Duarte - O Planejamento Estratégico e o Conceito de Performance Process na Gestão das Artes Revista Arte da Cena, Goiânia, v. 2, n. 2, p. 82-97, Jan.-Jun./2016 
custo, gestão do orçamento, alocação de recursos, comunicação. Fluxo de trabalho, gestão de qualidade, documentação, sistema administrativo. Esse é o lado, digamos, "administrativo e gerencial” do processo. Mas na arte existem obras que incluem ações virtuais, colaborativas na gestão e na realização da obra/processo. Nesse caso a gestão virtual se diferencia da gestão de projetos tradicional, as atividades e ações giram em torno do teletrabalho e colaboração global (no caso de trabalhos que incluem participação externas), com o uso do meio e ambiente virtual. Deste modo, a gestão estratégica inclui conhecimentos específicos dessas ações (muitas são desenvolvidas com artistas em diferentes localidades), dos meios a serem utilizados, e principalmente dos resultados desejados, previamente previstos ou não. E como não poderia deixar de faltar, a gestão virtual também se responsabiliza pelas questões relacionadas à autoria, definindo nos termos, os papéis dispensados para cada participante.

Neste ponto cabe buscar o conceito de Renato Cohen (2006) para confrontar a gestão estratégica com a natureza de muitas ações artísticas. Para pensar a arte enquanto processo, acionamos parte do termo cunhado por Renato Cohen (2006) -“work in progress” - para pensar o "work in process" da cena artística. Subvertendo o sentido clássico da narrativa, Cohen busca nos paradigmas contemporâneos da linguagem uma forma para teorizar a Performance, partindo da "estrutura" do hipertexto (caracterizado pela aleatoriedade e sincronicidade), que cogita o procedimento de criação cênica não como obra acabada, mas como obra em processo. O termo work in progress carrega a ideia tanto de trabalho e como de processo: como trabalho, acumulamse duas noções, o da obra acabada, como produto, e o de obra em processo de feitura, em percurso. Como processo, implica interatividade, permeação e risco (risco de o processo não se fechar enquanto obra acabada) (COHEN, 2006, p. 20-21). O autor nos mostra uma das realidades da obra de arte contemporânea: muitas se realizam como processo, um processo que deve ser planejado com antecedência, mas que pode ser tomado pelos acasos ao longo do percurso (como intenção da obra). Nesse caso, a gestão de projetos trata principalmente do escopo "gerencial", da organização do tempo e dos custos finais da produção. Mesmo para as obras que se desenvolvem durante muitos anos, podese inferir que em algum momento essa "obra" venha a ser apresentada a público, determinando a necessidade do planejamento e gestão.

\section{CONCLUSÃO}

A gestão estratégica - Project Management - em artes é uma forma eficiente de realização da prática artística e organização dos meios de

Valquiria Guimarães Duarte - O Planejamento Estratégico e o Conceito de Performance Process na Gestão das Artes Revista Arte da Cena, Goiânia, v. 2, n. 2, p. 82-97, Jan.-Jun./2016 


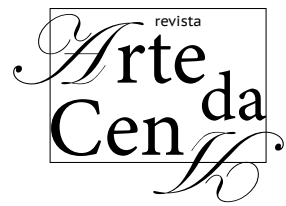

produção, dentro dos anseios do artista e de seu projeto. Pela natureza da arte contemporânea, hoje se torna imprescindível o planejamento detalhado da obra, com definição de etapas, prazos e responsabilidades. O que anteriormente poderia ser impensável no âmbito das artes - o artista terceirizar a execução de sua obra, ou o processo de produção - é um fator determinante no sucesso do empreendimento, seja ele de crítica ou de público. Mesmo as ações que não tem como intenção passar pelo crivo dos especialistas, muitas só conseguem ser realizadas a partir de um processo minimamente detalhado e organizado previamente.

Assim, o quadro dos empreendimentos artísticos, hoje, pode ser comparado à arquitetura e construção civil: quanto mais o "edifício" é planejado anteriormente, menores os riscos e maiores os resultados - o que não diminui a importância ou o lugar do artista como autor de sua obra. Para finalizar, podemos afirmar que muitas obras de arte ou proposições teatrais não saem do papel pela falta de profissionalização na gestão, desde a captação de recursos ao desenvolvimento do empreendimento. Nesse sentido, se torna válido buscar nas experiências da arquitetura experiências que possam alimentar o campo da gestão das artes.

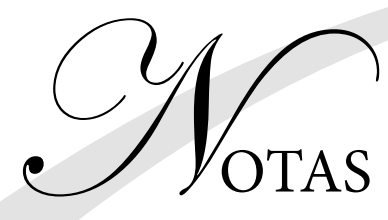

1 Essa realização, em grande medida, em ações culturais, dependem de editais cada vez mais exigentes quanto ao detalhamento das proposições.

$2 \mathrm{Na}$ tese intitulada "Uma História Edificada: Tríplice Mimese e Performance. um estudo narrativo da Fundação Iberê Camargo (Porto Alegre- RS, 1998-2008), de Álvaro Siza, de Duarte (2013), sob orientação do Professor Doutor Marcio Pizarro Noronha no PROGRAMA DE PÓS-GRADUAÇÃO EM HISTÓRIA FH UFG, são desenvolvidos cinco conceitos analíticos para uma hermenêutica/ crítica da arquitetura. Partindo da observação do conceito de Performance Artística - principalmente dos fenômenos de processo, dinâmica e acaso e comparando com o fenômeno arquitetônico contemporâneo (projeto e construção), sugerimos uma operação transdisciplinar, nomeando os seguintes conceitos: Performance Conceitual, Performance Process, Techno Performance, Performance (In) Doors, (Out), Doors, Arquitetura Performática.

O conceito de Performance Process também possibilita uma hermenêutica do campo da arquitetura: o que também se tem em vista éa memória que gira em torno do fenômeno arquitetônico. As relações arquitetura x performance são investigadas na efetivação do projeto e no processo de sua realização, surgindo daí a ideia do arquiteto como narrador e do projeto como narrativa não-linear. A operação proposta é a de cruzar o espaço e o tempo através dos atos de "construir" e narrar: ao fundir a espacialidade do relato e a temporalidade do ato

Valquiria Guimarães Duarte - O Planejamento Estratégico e o Conceito de Performance Process na Gestão das Artes Revista Arte da Cena, Goiânia, v. 2, n. 2, p. 82-97, Jan.-Jun./2016 
“construtivo" encontramos a dialética da memória e a obra em um mesmo núcleo de atividade.

4 Project Management ou o gerenciamento de projetosé a disciplina de iniciação, planejamento, execução, controle e encerramento dotrabalhode umaequipepara atingir objetivos específicos e atender a critérios específicos de sucesso. Umprojetoé um esforço temporário concebido para produzir um produto único, serviço ou resultado com um começo e fim definidos (geralmente em tempo limitado, e muitas vezes constrangidos por financiamento ouprestações). É um empreendimento que visa atingir metas e objetivos únicos, geralmente trazendo mudanças benéficas de qualificação e valorização. A natureza temporária dos projetos está em contraste com obusiness as usual - ou operações comuns-, que são repetitivas, permanentes ou semi permanentes - atividades funcionais para produzir produtos ou serviços.Na prática, agestãodestes dois sistemas é muitas vezes bastante diferente, e, como tal, exige o desenvolvimento de competências técnicas distintas e estratégias de gestão.O principal desafio do project management é atingir todas as metas do projeto, dentrodoslimitesindicados. Estasinformações (plano estratégico de ação) são geralmente descritas em um manual do usuário ou projeto, que é criado no início do processo de desenvolvimento.As fases principais (não necessariamente cronológicas) sãoescopo, tempo, qualidade e orçamento. O secundário - e mais ambicioso - desafio éotimizaraalocaçãode insumos necessários e integrá-los de forma a cumprir os objetivos pré-definidos. Atualmente existe uma associação que tem como objetivo o desenvolvimento de métodos além da certificação de seus membros: aProject Management International Association(IPMA), fundada na Europa em 1967 como uma federação de várias associações nacionais de gestão de projeto, mantém sua estrutura até hoje, e agora inclui associações-membros em todos os continentes, exceto na Antártida. A IPMA oferece um programa de certificação em quatro níveis com base na IPMA Competence Baseline (ICB). O ICB abrange técnica, contexto e competências comportamentais.

5 Project Manager diz respeito a uma formação específica de gerência de projetos, que trata da administração de "todo" o processo de realização de um empreendimento, do planejamento (contratação de profissionais) até a finalização. Os gerentes de projetopodemtera responsabilidadedoplanejamento, execução e fechamento de qualquer projeto, normalmente relativas àindústria da construção civil, engenharia, arquitetura,computaçãoe telecomunicações.Muitos outros campos em engenharia de produção, engenharia de design, industrial e pesada têm gerentes de projeto. Um gerente de projeto é a pessoa responsável por realizar os objetivos do projeto declarados em escopo. As principais responsabilidades de gestão de projetos incluem a criação de objetivos claros e atingíveis projeto, construção dos requisitos do projeto e gerenciamento darestrição triplade projetos, que são o custo, tempo e escopo. Um gerente de projeto é muitas vezes um representante do cliente e tem que determinar e implementar as necessidades exatas do cliente, com base no conhecimento da empresa que está representando.A capacidade de adaptação aos vários procedimentos internos da parte contratante, e a formação de laços com os representantes designados, é essencial para garantir que as principais questões de custo, tempo, qualidade, e acima de tudo, a satisfação do cliente, pode ser realizado. A formação de Project Management (gerência global na construção civil) não é comum no Brasil; de uma maneira geral não há um responsável pelo processo global da obra. O Gerente de Projetos, que seria a tradução literal de Project Manager, é um arquiteto (Gerente de projetos de arquitetura) ou engenheiro (Gerente de projetos de engenharia) responsável

Valquiria Guimarães Duarte - O Planejamento Estratégico e o Conceito de Performance Process na Gestão das Artes Revista Arte da Cena, Goiânia, v. 2, n. 2, p. 82-97, Jan.-Jun./2016 
pelos projetos de arquitetura ou engenharia dentro de um escritório ou empresa.

${ }^{6}$ O Anteprojeto de arquitetura é o desenho gráfico básico para a aprovação nos órgãos responsáveis e as informações básicas construtivas. Aqui não estão contidos os detalhamentos dos acabamentos nem os cálculos dos projetos complementares de engenharia.

${ }^{7}$ Para Melhado (2012), é de fundamental importância que o cliente dê autonomia à coordenação dos projetos, "de modo que ela possa atuar e tomar decisões, e possa solicitar respostas dos projetistas para as necessidades encontradas, conferindo-lhe, assim, a autonomia necessária à gestão do processo de projeto" (MELHADO, 2012, p.1).

${ }^{8}$ Podemos exemplificar uma obra que teve como base a gerência estratégica de planejamento: a Fundação Iberê Camargo, centro cultural/museu instalado na orla do Guaíba, em Porto Alegre (1989-1999).

9 Se considerarmos a arquitetura seriada, podese afirmar que no Brasil os custos de projeto arquitetônico muitas vezes inviabilizam a consultoria prévia das engenharias.

\section{O Projeto Executivo em arquitetura é o} detalhamento do Anteprojeto (projeto básico para aprovação nos órgãos competentes), e diz respeito às informações suficientes para a realização de um empreendimento. Esse detalhamento abrange revestimentos, iluminação, conforto térmico, acústico, paisagismo, mobiliário, equipamentos, redes, etc.

11 Aqui diferenciamos o papel do curador, do diretor/produtor artístico, do project manager. $\mathrm{O}$ curador é o profissional responsável pela preparação, concepção e montagem de exposições. Seu papel é estabelecer relações entre as obras e fazer com que dialoguem com o público. Como o curador do Museu de Arte Moderna (MAM) do Rio de Janeiro, Luiz Camillo Osorio compara, "É como um técnico de futebol, que escolhe o time, pegando os melhores jogadores para cumprir sua função". O diretor de arteé o profissional que geralmente gerencia a atividade de design e concepção artística de um produto audiovisual, incorporando uma série de funções, em publicidade, design editorial, internet, videogames cinema e propaganda. $\mathrm{O}$ produtor artístico trabalha em conjunto, principalmente, com o diretor de arte, fazendo com que toda a parte visual aconteça. No caso do diretor de uma peça teatral ou cinema, a estratégia e atividades são diferentes do produtor: ele é o profissional que trabalha em consonância com o diretor geral, que supervisiona e dirige a execução das filmagens, utilizando recursos humanos, técnicos, gramáticos e artísticos. O diretor pode ser um profissional, por exemplo, contratado para realizar o projeto da peça ou cinema.

${ }^{12}$ No caso de gerência de projetos artísticos, muitas vezes o projeto fica parado à espera de um edital de concorrência pública. Com um planejamento estratégico pode-se reutilizar a proposta para vários programas de fomento. Para tanto, o escopo deve apresentar as informações necessárias que se apresentam em comum em todos os processos de realização de projetos, como por exemplo, o conceito, modelos, roteiros, etc. desenvolvidos de forma profissionalizada, dentro de normas técnicas.

Valquiria Guimarães Duarte - O Planejamento Estratégico e o Conceito de Performance Process na Gestão das Artes Revista Arte da Cena, Goiânia, v. 2, n. 2, p. 82-97, Jan.-Jun./2016 


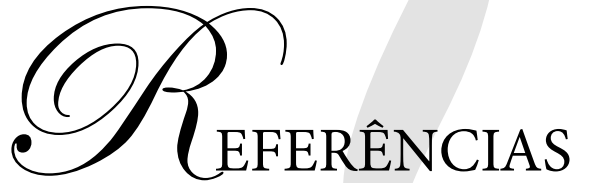

COHEN, Renato. Work in progress na cena contemporânea: criação, encenação e recepção. São Paulo: Perspectiva, 2006.

.Performance como linguagem. $2^{\circ}$ edição. São Paulo: Perspectiva, 2009.

DUARTE, Valquíria G. Uma História Edificada: Tríplice Mimese e Performance. Um Estudo Narrativo da Fundação Iberê Camargo (Porto Alegre-RS, 1998-2008), de Álvaro Siza. Tese (Doutorado) - Programa de Pós-Graduação em História da Universidade Federal de Goiás. Goiânia, 2013.

DUARTE, Valquíria G.; NORONHA, Márcio Pizarro. Performance e arquitetura: uma transmutação conceitual a partir do estudo do edifício da Fundação Iberê Camargo, de Álvaro Siza. In: Anais do II Congresso Internacional de História da UFG de Jataí. Jataí, 2011.

GONÇALVES, C. M. M.; MELHADO, S. B. Método para gestão do custo da construção no processo de projeto de edifícios: EPUSP, 2011. 27p. (Boletim Técnico da Escola Politécnica da USP, Departamento de Engenharia de Construção Civil, BT/PCC/573).

MEDEIROS, M. C. I. ; MELHADO, S. B. Gestão do conhecimento aplicada ao processo de projeto na construção civil: estudo de caso em construtoras. São Paulo: EPUSP, 2013. 24 p. (Boletim Técnico da Escola Politécnica da USP, Departamento de Engenharia de Construção Civil, BT/PCC/581).
MELHADO, S. B. Qualidade do projeto na construção de edifícios: aplicação ao caso das empresas de incorporação e construção. Tese (Doutorado) - Escola Politécnica, Universidade de São Paulo. São Paulo, 1994.

Coordenação de projetos - atribuições e responsabilidades. Disponível em: $\quad$ http://www.aecweb.com.br/artigo/ gerenciamento-de-obras/402/silvio-melhado/ coordenacao-de-projetos-atribuicoes-eresponsabilidades.html. Acesso: 01. nov. 2012.

MENDONÇA, Ana Domitila de A.; JAPIASSÚ, Pamilla; CORREA, Wanessa; AMARAL, Tatiana Gondim do. A gestão do processo de projeto da gerência de planejamento e projeto da Universidade Federal de Goiás. Anais do XIII Encontro Nacional de Tecnologia do Ambiente Construído. Canela, 2010.

NOKES, Sebastian.The Definitive Guide to Project Management. London (Financial Times / Prentice Hall), 2007.

NORONHA, Marcio. Economia das artes. Goiânia: Gráfica Qualicor, 2015. Projeto da Lei Municipal de Incentivo à Cultura de Goiânia.

NORONHA, Marcio Pizarro e BATISTA, Sandro Tôrres. Essa tal arte contemporânea. Goiânia: Gráfica e Editora América, 2012. Projeto da Lei Municipal de Incentivo à Cultura de Goiânia.

SOURIAU, Étienne. A correspondência das artes: elementos de estética comparada. Trad. Maria Cecília Queiroz de Moaes Pinto e Maria Helena Ribeiro da Cunha. São Paulo: Cultrix/ Edusp, 1983.

Valquiria Guimarães Duarte - O Planejamento Estratégico e o Conceito de Performance Process na Gestão das Artes Revista Arte da Cena, Goiânia, v. 2, n. 2, p. 82-97, Jan.-Jun./2016 
* VAlQUiRIA GUIMARÃES DUARTE é doutora em História pela Universidade Federal de Goiás (2013), com a tese "Uma História Edificada: Tríplice Mimese E Performance. Um Estudo Narrativo da Fundação Iberê Camargo (Porto Alegre RS 1998-2008), de Álvaro Siza”. É mestre em Patrimônio Cultural pela Universidade Católica de Goiás (2004) e graduada em Arquitetura e Urbanismo pela mesma universidade (1988). Atuou, de 2002 a 2015 como docente da Faculdade de Artes Visuais da UFG, no curso de Design de Ambientes. Tem experiência na área de Arquitetura, Design e Patrimônio Cultural. Pesquisa os seguintes temas: História da Arquitetura e do Design, participa do grupo de pesquisa (CNPQ) INTERARTES: PROCESSOS E SISTEMAS INTERARTÍSTICOS E ESTUDOS DE PERFORMANCE, nas linhas de pesquisa "Estudos de Performance, Body Art, Narratividade e Artes Espaciais", "Estudos do Espaço: História da Arte e da Arquitetura enquanto Arte e Museus de Arte enquanto paradigma" e "Historiografia da História das Artes e Teorias da Imagem, do Corpo e do Audiovisual - História Plural e Comparada das Artes". Atualmente atua como consultora junto ao Ministério Público do Estado de Goiás, em um Programa de Acessibilidade em edifícios e centros urbanos, e no Centro de Gestão do Espaço Físico da Universidade Federal de Goiás, em projetos de arquitetura e urbanismo dos campi da universidade.

Valquiria Guimarães Duarte - O Planejamento Estratégico e o Conceito de Performance Process na Gestão das Artes Revista Arte da Cena, Goiânia, v. 2, n. 2, p. 82-97, Jan.-Jun./2016 